\title{
Visualizing Proximity of Non-Native Species to Protected Areas of the United States-A Proximity Visualization Tool for BISON
}

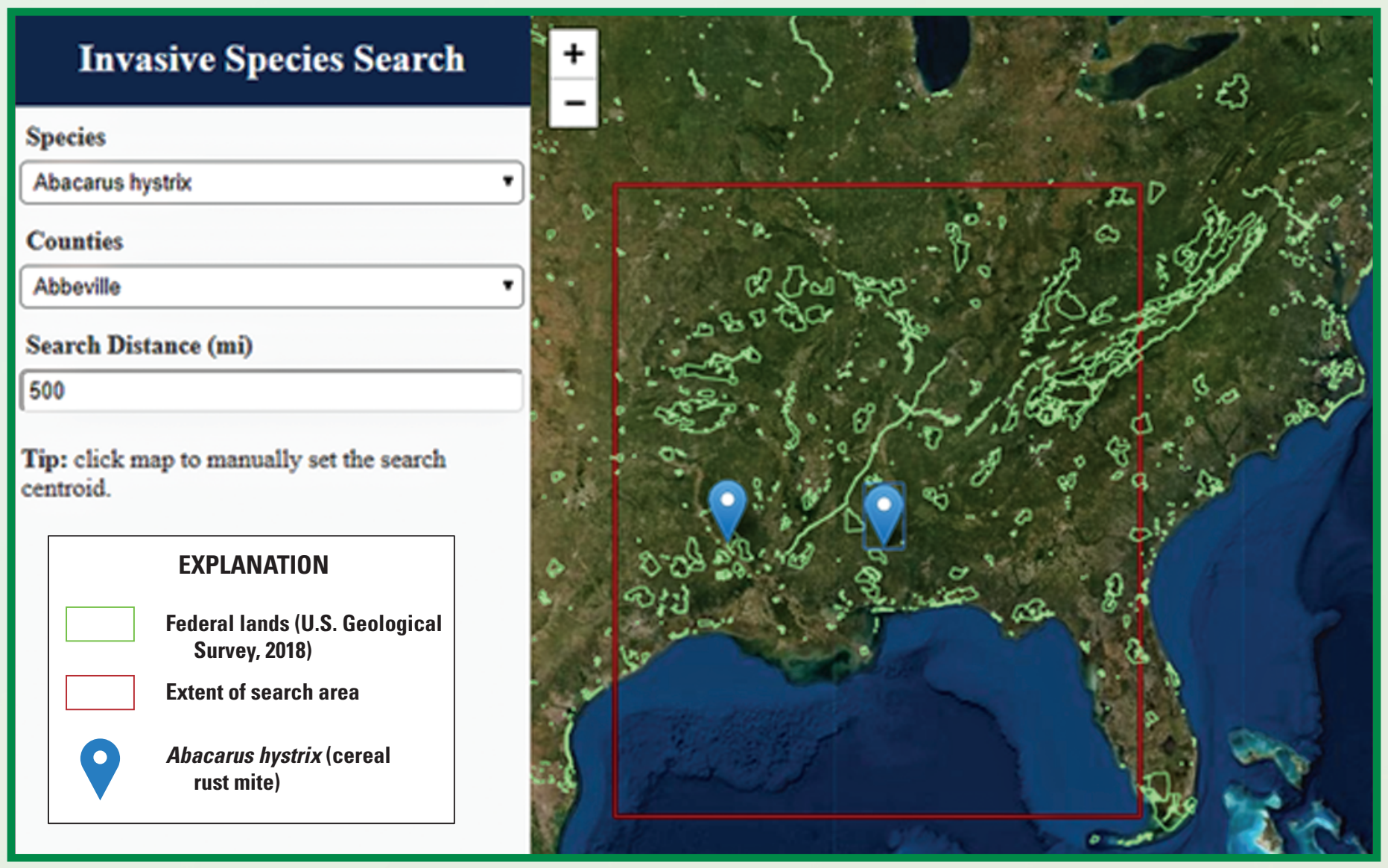

Figure 1. A close up of the Invasive Species Search for a clicked location. The lime green polygons are protected lands, blue markers are Abacarus hystrix (cereal rust mite) occurrences, and the red square shows the extent of the search area.

The Proximity Visualization Tool is a simple lightweight tool that can be placed on web pages that allows users to identify non-native species near Department of Interior lands. The tool works by accessing the more than 400 million species occurrence records in the Biodiversity Information Serving Our Nation (BISON) database using the BISON Application Programming
Interface (API). The tool sends user-defined spatial and species selections to the BISON API, and the BISON API returns instances of non-native species near protected areas (U.S. Geological Survey Gap Analysis Project, 2018) within the selected spatial boundary. The tool is available from the BISON Examples page (https://bison .usgs.gov/examples.html). 
When an input in the Invasive Species Search filter is changed (fig. 1), the tool automatically queries the BISON API using the newly selected filters. The search filter includes dropdown options for all non-native species known to be present in the United States from a comprehensive list of non-native species (Simpson and others, 2019) and U.S. counties and a text field to input search distance (in miles) around the selected county.

Additionally, a user can change the search location by clicking the map, which will automatically requery the BISON database using the map coordinates from the user-selected location, excluding the selected county input. The map can also be zoomed to search in small and large units of protected lands with no restriction on search distance. This allows users to efficiently search the more than 400 million records contained in BISON to identify non-native species occurrences in proximity to the selected spatial area of interest.

The tool can be extended to include features for downloading data, filtering by occurrence time, and adding new state land database layers. Finally, the tool was built to show the great benefits and slight shortcomings of BISON, so it should only be used as an example of BISON usage: there is no application maintenance, support, or adverse event reporting.

\section{References Cited}

Simpson, A., Eyler, M.C., Sikes, D., Bowser, M., Sellers, E., Guala, G.F., Cannister, M., Libby, R., and Kozlowski, N., 2019, A comprehensive list of non-native species established in three major regions of the United States: Version 2.0, (ver. 2.0, 2019): U.S. Geological Survey data release, https://doi.org/10.5066/ P9E5K160.

U.S. Geological Survey Gap Analysis Project, 2018, Protected Areas Database of the United States (PAD-US) 2.0: U.S. Geological Survey data release, https://doi.org/10.5066/P955KPLE.
For additional information contact:

Director, Upper Midwest Environmental Sciences Center

2630 Fanta Reed Road

La Crosse, WI 54603

United States
By Travis J. Harrison, Enrika Hlavacek, and Jennifer Dieck 